mends that matching for class I (HLA-A and HLA-B) should be offered in high risk cases. Limitation of matching to only the A and B loci will maximise the donor pool available and minimise waiting times. Recommendations about class II (HLA-DR) matching must await the outcome of further studies.

Department of Ophthalmology,

School of Medical Sciences

University Walk, Bristol BS8 1TD

1 The Collaborative Corneal Transplantation Studies Research Group. Effectiveness of histocompatibility matching in high-risk corneal transplantation. Arch Ophthalmol 1992;110:1392-403.

2 Baggesen K, Ehlers N, Lamm LU. HLA-DR/RFLP compatible corneal Baggesen K, Ehlers N, Lamm LU. HL

3 Vail A, Gore SM, Bradley BA, Easty DL, Rogers CA, Armitage WJ, on behalf of the Corneal Transplant Follow-up Study Collaborators. Influence of donor and histocompatibility factors on corneal graft outcome. Transplantation 1995;58:1210-7.

4 Assouline M, Delbosc B, Rigal D, Adenis JP, Bechetoille A, Sabatier P, et al. Survival of high risk HLA matched penetrating keratoplasty. Vision Res 1995;85 (suppl):S83.

5 Opelz G. Influence of HLA matching on survival of second kidney transplants in cyclosporin-treated recipients. Transplantation 1989;47:823-7.

6 Dyer PA, Johnson RWG, Martin S, Bakran A, Gokal R, Harris R, et al. Evidence that matching for HLA antigens significantly increases transplant survival in 1001 renal transplants performed in the northwest region of survival in 1001 renal transplants perfo

7 Larkin DFP. Corneal allograft rejection. Brf Ophthalmol 1994;78:649-52.

8 Katami M, White DJG, Watson PG. An analysis of corneal graft rejection in the rat. Transplant Proc 1989;21:3147-9.

9 Nicholls SM, Bradley BA, Easty DL. Effect of mismatches for major histocompatibility complex and minor antigens on corneal graft rejection. Invest Ophthalmol Vis Sci 1991;32:2729-34.
10 Nicholls SM, Bradley BA, Easty DL. Apparent resistance to immunosuppression of MHC-matched corneal transplants. Transplantation 1995;59. 325-8.

11 Sonoda Y, Streilein JW. Orthotopic corneal transplantation in miceevidence that the immunogenetic rules of rejection do not apply. Transplantation 1992;54:694-704.

12 Batchelor JR, Casey TA, Werb A, Gibbs D, Prasad SS, Lloyd, et al. HLA matching and corneal grafting. Lancet 1976;i:551-4.

13 Schreuder GMT, Pool J, Blokland E, van Els C, Bakker A, van Rood J, et al. A genetic analysis of human minor histocompatibility antigens demonstrates Mendelian segregation independent of HLA. Immunogenetics 1993; 38:98-105.

14 Wang W, Meadows LR, den Haan JMM, Sherman NE, Chen Y, Blokland E, et al. Human H-Y: a male-specific histocompatibility antigen derived from the SMCY protein. Science 1995;269:1588-90.

15 Goulmy E, Schipper R, Pool J, Blokland E, Falkenburg JH, Vossen J, et al. Mismatches of minor histocompatibility antigens between HLA-identical donors and recipients and the development of graft-versus-host disease after bone marrow transplantation. $N$ Engl F Med 1996;334:281-5.

16 Goulmy E, Pool J, van Lochem E, Volker-Dieben H. The role of human minor histocompatibility antigens in graft failure: a mini-review. Eye 1995; 9:180-4.

17 Lechler RI, Batchelor JR. Restoration of immunogenicity to passenger celldepleted kidney allografts by the addition of donor strain dendritic cells. $\mathcal{F}$ Exp Med 1982;155:31-41.

18 Willams KA, Mann TS, Ash JK, Coster DJ. The role of resident accessory cells in corneal allograft rejection in the rabbit. Transplantation 1986;42: 667-71.

19 Williams KA, Ash JK, Coster DJ. Histocompatibility antigen and passenger cell content of normal and diseased human cornea. Transplantation 1985;39:265-9.

20 Williams, KA, White MA, Ash JK, Coster DJ. Leucocytes in the graft bed are associated with corneal graft failure: analysis by immunohistology and actuarial graft survival. Ophthalmology 1989;96:38-44.

21 Pepose JS, Gardiner, Nestor MS, Foos RY, Pettit TH. Detection of HLA class I and II antigens in rejected human corneal allografts. Ophthalmology 1985;92:1480-4.

22 Ayliffe W, Alam Y, Bell EB, McLeod D, Hutchinson IV. Prolongation of rat corneal graft survival by treatment with anti-CD4 monoclonal antibody. $B r$ f Ophthalmol 1992;76:602-6.

\title{
The ophthalmic physician: an indulgence or a necessity?
}

Surgical advances in ophthalmology have been spectacular during the past few decades and have radically changed the practice of ophthalmology. Accordingly, the late 20th century trainee devotes much of his time rightly honing his skills in surgical manoeuvres and most of the subspecialisation in ophthalmology is surgically orientated, as emphasised by the standards and knowledge expected in fellowship examinations and for higher surgical training in ophthalmology. However, all ophthalmologists are aware that a large part of our practice relates to medical problems for which there is no surgical treatment. Many fields of general medicine are involved such as rheumatology, neurology, endocrinology and diabetology, cardiovascular disease, and inflammatory/infectious disease. Some of the conditions which are included in these spheres of practice, such as keratoconjunctivitis sicca and infectious anterior segment disease, can be adequately treated by the 'primary care ophthalmologist' with appropriate subspecialist referral when indicated. However, as a result of recent research developments, treatments and cures for many medical ophthalmic conditions are now available and it therefore becomes a major responsibility to ensure that these treatments are properly delivered and monitored. Patient management and research development into these conditions have, to date, been performed with liaison between ophthalmologist and physicians or by a few ophthalmologists who have chosen to take that path. Ophthalmologists have to feel comfortable knowing that they can adequately manage and treat patients without overburdening our equally stretched physician colleagues.

Currently the major blinding disease in the developed world is macular degeneration. However, in the working age population diabetic retinopathy and chronic uveitis represent two major causes of blindness. While most ophthalmologists feel confident in their management of the former, the fact that the latter is a curable/preventable cause of blindness is less well recognised. Treatment of chronic uveitis is now best achieved with long term immunosuppression but few ophthalmologists have the experience to feel secure in the long term use of drugs such as cyclosporin A and methotrexate, while physicians are not trained to recognise the ophthalmological end points which can determine necessary changes to treatment regimens.

A new kind of ophthalmologist is therefore required: one who is skilled in ophthalmic medical diagnosis, in relating systemic medical disease to ophthalmic conditions, in assessing the general medical status of patients who have primary ophthalmological disease, and in prescribing the most appropriate drug therapies and monitoring schedules for treatment of medical sight threatening diseases.

Recognition of the need for medical ophthalmologists has resulted in the Royal College of Ophthalmologists and Royal College of Physicians jointly establishing a professional training programme leading to accreditation and registration on the specialist register in the new subspecialty of medical ophthalmology - that is, a training for the ophthalmic physician. Currently, entry to the new training programme may be gained from a background in general medicine or general ophthalmology and the training programme appropriately tailored in line with a general template which ensures full exposure to the various aspects of medical ophthalmology. This training programme is in its infancy, but it is already clear that the route of entry to a medical ophthalmic training programme is less important than how we are going to provide training. Relevant postgraduate general medical training at some stage, however, appears appropriate. When medical ophthalmology as a specialty has become sufficiently well established in the number of trained specialists, it will be in a better posi- 
tion to dictate its own training programmes alongside its surgical counterpart.

Does ophthalmology need ophthalmic physicians? Ophthalmology has now become so effective in the management of many aspects of medical ophthalmology that specific training is probably the only way to gain experience and skills. Some examples are given below.

Diabetic retinopathy is predominantly the remit of the medical ophthalmologist. Not only can they provide specialist expertise in the treatment of active retinopathy but many of the decisions determining when and how much laser therapy to apply require expert opinion. In addition, the decision when to refer to the vitreoretinal surgeon is often a critical one. The decision on which patients require follow up in an ophthalmology clinic or can be safely reviewed by diabetologists and primary care physicians, as well as offering general diabetological advice, may also be difficult.

Ocular inflammatory disease (uveitis) is a particularly difficult field, often left to inexperienced staff who are not sufficiently trained in the correct use of immunosuppressive therapy. Accordingly, many patients are referred to tertiary referral centres too late with significant and permanent visual loss. Another particular subgroup requiring special expertise are the immunosuppressed patients with infective retinitis who require high levels of pharmacological knowledge on the part of their physician to ensure best clinical care.

Rheumatological disease includes a very wide spectrum of anterior segment disease such as corneal melts and scleritis in addition to the large numbers of patients with keratoconjunctivitis sicca. Besides many new topical and systemic drugs arriving on the market, general patient management including appropriate investigations requires increasing levels of physician awareness.

Cardiovascular disease includes much of the 'classic' medical ophthalmological conditions such as hypertensive retinopathy and vaso-occlusive disease. However, because of recent advances in our understanding of coagulopathies, including the factor $\mathrm{V}$ Leiden mutation and antiphospholipid anomalies, patient management will require not only considerable awareness of aetiology and pathogenesis and a physician input other than instituting appropriate medical therapy but also a knowledge of medical genetics and counselling techniques.

Endocrine disease, particularly of the thyroid, is increasingly important as non-surgical options to the management of dysthyroid eye disease, including immunosuppression and radiotherapy, become more commonly used.

Neuro-ophthalmology may include skills in botulinum therapy, in the investigation and management of patients with optic neuritides and retinal degenerations, in addition to the established role of the neuroophthalmologist.

There could be many other examples cited. Indeed, the subspecialty of 'medical retina' is probably within the domain of the ophthalmic physician but alone is too narrow a focus for the trained ophthalmic physician. Clearly it is outside the remit of the ophthalmic surgeon who has already subspecialised as an anterior segment surgeon, a vitreoretinal surgeon, paediatric ophthalmologist, ophthalmic oncologist, ocular motility expert, or a glaucoma specialist, also to have sufficient general medical knowledge to allow him to manage many of the above medical conditions safely and effectively. Patients, however, can by right expect appropriate treatment if it is likely to result in amelioration of their condition.

While the professional bodies may have seen the light, changes in the way we practise have not permeated to the front lines mainly because there are so few specialty trained medical ophthalmologists or ophthalmic physicians. Ophthalmologists have to be willing also to give equal support and encouragement for the development of this specialty and, with the introduction of structured training programmes, it is surely perfect timing to encourage the necessary expansion in medical ophthalmic training. In particular, employing authorities and hospital trusts are probably unaware of this fundamental change in practice especially as the highest priority in appointing new specialists is seen as efficient management and reduction of surgical waiting lists. Many questions remain to be answered including how many ophthalmic physicians does the country need? What ratio of ophthalmic physicians to ophthalmic surgeons will a typical unit have? Who will appoint these new specialists and what will be their job plans? The answers are eagerly awaited as both patients and ophthalmology would benefit from this fruitful expansion.

ANDREW D DICK JOHN V FORRESTER

Department of Ophthalmology,

University of Aberdeen, Scotland 